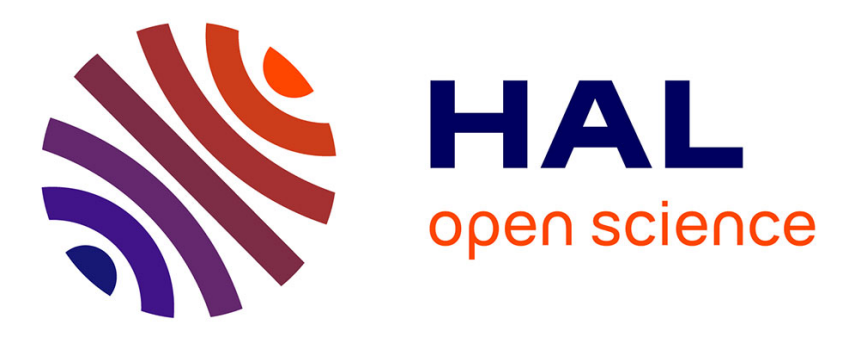

\title{
Antiproliferative And Antiangiogenic Effects Of The Benzophenanthridine Alkaloid Sanguinarine In Melanoma
}

Ilaria de Stefano, Giuseppina Raspaglio, Gian Franco Zannoni, Daniele Travaglia, Maria Grazia Prisco, Marco Mosca, Cristiano Ferlini, Giovanni Scambia, Daniela Gallo

\section{To cite this version:}

Ilaria de Stefano, Giuseppina Raspaglio, Gian Franco Zannoni, Daniele Travaglia, Maria Grazia Prisco, et al.. Antiproliferative And Antiangiogenic Effects Of The Benzophenanthridine Alkaloid Sanguinarine In Melanoma. Biochemical Pharmacology, 2009, 78 (11), pp.1374. 10.1016/j.bcp.2009.07.011 . hal-00524466

\section{HAL Id: hal-00524466 \\ https://hal.science/hal-00524466}

Submitted on 8 Oct 2010

HAL is a multi-disciplinary open access archive for the deposit and dissemination of scientific research documents, whether they are published or not. The documents may come from teaching and research institutions in France or abroad, or from public or private research centers.
L'archive ouverte pluridisciplinaire $\mathbf{H A L}$, est destinée au dépôt et à la diffusion de documents scientifiques de niveau recherche, publiés ou non, émanant des établissements d'enseignement et de recherche français ou étrangers, des laboratoires publics ou privés. 


\section{Accepted Manuscript}

Title: Antiproliferative And Antiangiogenic Effects Of The Benzophenanthridine Alkaloid Sanguinarine In Melanoma

Authors: Ilaria De Stefano, Giuseppina Raspaglio, Gian Franco Zannoni, Daniele Travaglia, Maria Grazia Prisco, Marco Mosca, Cristiano Ferlini, Giovanni Scambia, Daniela

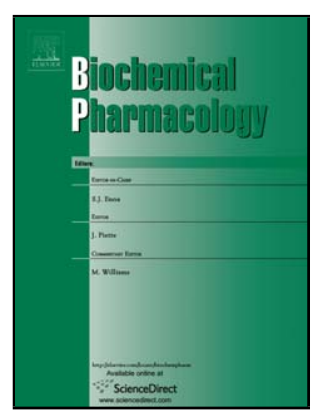

Gallo

PII:

S0006-2952(09)00643-1

DOI: doi:10.1016/j.bcp.2009.07.011

Reference: BCP 10268

To appear in: $\quad B C P$

Received date: $\quad 8-6-2009$

Revised date: $\quad$ 16-7-2009

Accepted date: $\quad$ 17-7-2009

Please cite this article as: De Stefano I, Raspaglio G, Zannoni GF, Travaglia D, Prisco MG, Mosca M, Ferlini C, Scambia G, Gallo D, Antiproliferative And Antiangiogenic Effects Of The Benzophenanthridine Alkaloid Sanguinarine In Melanoma, Biochemical Pharmacology (2008), doi:10.1016/j.bcp.2009.07.011

This is a PDF file of an unedited manuscript that has been accepted for publication. As a service to our customers we are providing this early version of the manuscript. The manuscript will undergo copyediting, typesetting, and review of the resulting proof before it is published in its final form. Please note that during the production process errors may be discovered which could affect the content, and all legal disclaimers that apply to the journal pertain. 


\section{ANTIPROLIFERATIVE AND ANTIANGIOGENIC EFFECTS OF THE BENZOPHENANTHRIDINE ALKALOID SANGUINARINE IN MELANOMA}

Ilaria De Stefano ${ }^{1 *}$, Giuseppina Raspaglio ${ }^{1 *}$, Gian Franco Zannoni ${ }^{2}$, Daniele Travaglia ${ }^{1}$, Maria

Grazia Prisco ${ }^{1}$, Marco Mosca ${ }^{1}$, Cristiano Ferlini ${ }^{1}$, Giovanni Scambia ${ }^{1}$, and Daniela Gallo ${ }^{1}$.

${ }^{1}$ Laboratory of Antineoplastic Pharmacology, Department of Obstetrics and Gynecology, Catholic

University of the Sacred Heart, Rome, Italy

${ }^{2}$ Department of Histopathology, Catholic University of the Sacred Heart, Rome, Italy

*These Authors equally contributed to this work.

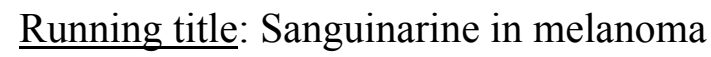

Correspondence to:

Dr. Daniela Gallo

Laboratory of Antineoplastic Pharmacology

Department of Obstetrics and Gynecology

Catholic University of the Sacred Heart, Rome, Italy

Largo A. Gemelli, 8 - 00168 - Rome - Italy

Tel +39063013337

Fax. +390635508736

e-mail: d.gallo@rm.unicatt.it 


\begin{abstract}
This study was aimed at evaluating the potential application of benzophenanthridine alkaloids, sanguinarine and cheleritrine, in the therapy of melanoma cancer. In vitro antiproliferative activity of sanguinarine was higher than that of cheleritrine against the B16 melanoma 4A5 cells. Both agents were able to produce DNA breaks, and the DNA unwinding assay showed that they act as DNA intercalating agents. Sanguinarine was selected for determination of its in vivo preclinical efficacy. Oral treatment with sanguinarine reduced the tumor burden in a transplantable murine tumor grown in a syngenic host (B16 melanoma 4A5 in $\mathrm{C} 57 \mathrm{BL} / 6$ mice), and in a human tumor xenograft grown in immunodeficient mice (A375 human melanoma in athymic nude mice). In A375 tumors a significant decrease in the proliferation marker Ki67, and a reduction in the activated mitogen-activated protein kinases (p-p44/42 MAPK), and in protein kinase B (pAKT) were also observed. Three out of eleven A375-bearing treated mice were tumor-free at the end of treatment, and did not develop any tumor after a further, treatment-free, observation period of 60 days. Sanguinarine also showed a striking anti-angiogenic activity in mice. Data from the present study support the concept that sanguinarine can be effective in melanoma skin cancer.
\end{abstract}

Key words: sanguinarine, melanoma, angiogenesis, MAPK, mice 


\section{INTRODUCTION}

Malignant melanoma is an aggressive, therapy-resistant malignancy of melanocytes. The incidence of melanoma has been steadily increasing worldwide, resulting in an increasing public health problem. In Europe, 26368 males and 35909 females are diagnosed each year with melanoma, and around 8500 males and 8000 females die because of it [1]. In the United States, about 62480 cases of melanoma were expected to be diagnosed in 2008, with about 8 420 Americans dead from this cancer [2]. As with most malignant disorders, prognosis is highly dependent on the clinical stage (extent of tumor burden) at the time of diagnosis, and the patient's clinical stage at diagnosis dictates selection of therapy. If melanoma is diagnosed early it can be cured by surgical resection, and about $80 \%$ of cases undergo this treatment. However, metastatic malignant melanoma is largely refractory to existing therapies, and has a poor prognosis, with a median survival rate of 6 months, and a 5-year survival rate of less than 5\% [3]. There are several approved postoperative adjuvant therapies for malignant melanoma [3, and references therein]. Interferon- $\alpha$ (IFN- $\alpha$ ) is the most commonly used adjuvant immunotherapy for advanced melanoma, although its efficacy is still a matter of debate. High-dose interleukin-2 (IL-2) has also been approved, but response rates are low, and toxicity is a problem. Dacarbazine (DTIC) is the reference approved chemotherapeutic agent for the treatment of advanced melanoma, and drugs such as carmustine (BiCNU), paclitaxel (Taxol), temozolomide and cisplatin have shown single-agent activity in metastatic disease [4]. In addition, many different immunotherapies have been tested, but so far none of these approaches has reached regulatory approval [5]. Overall, despite decades of investigation, no systemic treatment that improves overall survival in patients with advanced metastatic melanoma has been developed, and new treatment options are urgently needed. Natural products have long been a fertile source of cure for cancer, with plant-derived drugs becoming increasingly explored and integrated into chemotherapy strategies; there are at least 
250,000 species of plants, out of which more than one thousand have been found to possess significant anticancer properties [6]. Recently, the benzophenanthridine alkaloids, which are mainly distributed in Papaveraceae (Chelidonium majus, Macleaya cordata, and Sanguinaria canadensis L), have been the focus of increasing attention for their anticancer activity [7-9]. Specifically, several studies have indicated that sanguinarine [13-methyl(1,3)benzodioxolo[5,6-c]-1,3-dioxolo[4,5-i] phenanthridinium], a compound endowed with antimicrobial, antioxidant, and anti-inflammatory properties [10, and the references therein], is able to inhibit the growth of various human cancer cell lines, at micromolar concentration, inducing a selective apoptotic response in cancer cells versus normal cells $[7,9,11]$. Notably, a recent study has also shown that sanguinarine reduces in vitro cell proliferation of K1375M2, a very invasive melanoma cell line; Authors reported that sanguinarine acts as a DNA damaging agent, showing also collateral damage to mitochondrial bioenergetics, in a fashion similar to doxorubicin [12].

In the present study, we have explored the potential application of benzophenanthridine alkaloids sanguinarine and cheleritrine in the therapy of melanoma cancer. To this end, in vitro antiproliferative activity of the compounds was investigated, along with their mechanism of action; sanguinarine was selected for preclinical in vivo evaluations. Results obtained demonstrated that the antitumoral effect of sanguinarine relies on its activity on several critical steps in primary tumor progression, including cell proliferation and angiogenesis. 


\section{MATERIALS AND METHODS}

\subsection{Drugs and reagents}

For in vitro studies, sanguinarine chloride and cheleritrine chloride (donated by INDENA Milan, Italy) were diluted in DMSO. Solutions were further diluted at each experimental day in order to achieve a $0.1 \%$ final DMSO concentration. All reagents were purchased from Sigma (Sigma- Chemical Co. St. Louis, Mo.), unless indicated.

\subsection{Cell Lines}

B16 melanoma 4A5 cells, a cell line derived from subcutaneously inoculated B16F0 tumors in C57BL/6 strain mouse, and A375 cells, derived from a 54 year old female with malignant melanoma, were purchased from the European Collection of Cell Cultures (ECACC, Salisbury, UK). Cells were grown in DMEM medium with $4500 \mathrm{mg} / \mathrm{L}$ glucose, supplemented with $10 \%$ fetal bovine serum, $1 \%$ non-essential amino acids mixture, $1 \%$ Kanamycin. Cells, propagated as a monolayer culture, were trypsinized twice weekly, and plated at a density of $10 \times 10^{4}$ cells per mL. All cultures were incubated at $37{ }^{\circ} \mathrm{C}$ under $5 \% \mathrm{CO}_{2}$ in a high humidity atmosphere.

\subsection{Growth inhibition assay}

B16 melanoma 4A5 cells were seeded (20 000 cells/well) in 96-well flat bottom plates (Viewplates, Perkin Elmer Life Science, Waltham, MA). After 24 hours, media were replaced and, after one washing, media containing the tested compounds were added. Three independent experiments were performed in quadruplicates. After $72 \mathrm{~h}$ of culture in the presence of the compounds, plates were harvested and the number of viable cells was estimated by dosing ATP, using the ATPlite kit (Perkin-Elmer Life Science), and the automated luminometer Topcount (Perkin-Elmer Life Science). For each compound a doseresponse curve was plotted, and the IC50 values were then calculated by fitting the concentration-effect curve data obtained in the three experiments with the sigmoid-Emax 
model using nonlinear regression, weighted by the reciprocal of the square of the predicted effect [13].

\subsection{Single cell gel electrophoresis (Comet assay)}

Nuclei were isolated from B16 melanoma 4A5 cells by incubating whole cells in a buffer containing $5 \mathrm{mM} \mathrm{MgCl}_{2}, 1 \mathrm{mM}$ EGTA, $1 \mathrm{mM} \mathrm{KH}_{2} \mathrm{PO}_{4}, 150 \mathrm{mM} \mathrm{NaCl}$, for $20 \mathrm{~min}$ on ice with gentle rocking. Plasma membrane disruption and nuclei integrity were checked under the microscope. Isolated nuclei were exposed to the drugs for $60 \mathrm{~min}$. Drug-untreated or $\mathrm{H}_{2} \mathrm{O}_{2}$ treated (50 $\mu \mathrm{M}$ for $5 \mathrm{~min}$ on ice) samples were run as negative and positive controls for DNA damage, respectively. DNA breaks were detected as described [14]. The calculations of the \%Tail DNA were carried out using the Kinetic Komet 5.0 software from Kinetic Imaging Ltd. (Liverpool, UK).

\subsection{Relaxation activity of Topoisomerase-I}

Topoisomerase-I (Topo-I) functional activity was assayed by relaxation of supercoiled plasmid DNA in a cell free system as described [14]. Images were acquired and quantified through the Phoretix 1D software package (Phoretix International Ltd, Newcastle, Tyne and Wear, UK).

\subsection{Measurement of DNA intercalation}

Intercalation was determined by the unwinding assay [15]. Supercoiled pBR322 DNA (Roche Diagnostics Corporation, Indianapolis, IN, USA) was relaxed with 300 U of Topo-I (Topogen, Port Orange, FL ) $\left(37^{\circ} \mathrm{C}, 15 \mathrm{~min}\right)$ in Topo-I relaxation buffer (Topogen). To confirm full relaxation of DNA, one sample was terminated with SDS after 75 min. Inhibitors were added and the incubations were continued for another $60 \mathrm{~min}$. The reaction was terminated by addition of $1 \%(\mathrm{w} / \mathrm{v})$ SDS. After digestion with proteinase K, open circular and linear DNA were separated from intact supercoiled and relaxed form, by agarose gel electrophoresis in the presence of $1 \mu \mathrm{g} / \mathrm{ml}$ ethidium bromide, under the same conditions as for 
the relaxation assay. The compounds were removed by extraction with chloroform/isoamyl alcohol (24:1), and topoisomers were separated on $1 \%$ agarose in Tris-Borate buffer. The gel was stained with ethidium bromide and acquired as described above.

\subsection{Animals}

Female C57BL/6, and female athymic mice [Athymic Nude-nu], 6 weeks old, were obtained from Charles River S.r.l. (Lecco, Italy), and housed under controlled conditions. The UKCCCR guidelines for the welfare of animals in experimental neoplasia were followed [16]. Studies were approved by the Animal Care and Use Committee of the Catholic University of the Sacred Heart (Rome, Italy), and by the Italian Ministry of Health.

\subsection{Tumor Growth}

On the day of inoculation, a suspension of B16 melanoma 4A5 $\left(2 \times 10^{5}\right)$ or A375 $\left(5 \times 10^{6}\right)$ cells was injected subcutaneously in C57BL/6 or athymic mice, respectively. Sanguinarine was dissolved in PEG 300: sterile water (1:2). Tumor-bearing mice received via gavage either $5 \mathrm{mg}$ sanguinarine/kg/day or vehicle ( $\mathrm{n}=10-12 \mathrm{mice} /$ group), daily, week-end off. Dosage used in this study was selected on the basis of previous unpublished data showing that the Maximum Tolerated Dose following oral chronic administration is $5 \mathrm{mg} / \mathrm{kg} /$ day. Body weight and tumor dimensions were measured two times per week. Due to excessive tumor ulceration, all mice bearing B16 melanoma 4A5 tumors were sacrificed on day 18 of the study; athymic mice bearing A375 xenografts were sacrificed when tumor weight was in the range of 1300$1500 \mathrm{mg}$. At sacrifice, blood was collected and serum frozen at $-20^{\circ} \mathrm{C}$ for analysis; all tumors were removed, and subsequently cut into two fragments: one-half of the tumor was snapfrozen in liquid nitrogen, before storage at $-80^{\circ} \mathrm{C}$ for protein analysis, the other half was fixed in $10 \%$ formalin and subsequently dehydrated and blocked in paraffin. 


\subsection{Evaluation of anti-tumor activity}

Tumor weight was calculated from two dimensional measurements (mm) [17]: Tumor weight $=$ length $\mathrm{x}$ width ${ }^{2} / 2$. The ratio between the mean tumor weight of treated mice and that of control mice x $100(\mathrm{~T} / \mathrm{C} \%)$ was assessed on each day of measurement. Differences in efficacy between treatment groups were expressed as the percentage of maximum tumor weight inhibition (TWI \%), calculated as follows: TWI $\%=100-\mathrm{T} / \mathrm{C} \%$. The optimum value for tumor weight inhibition obtained during the study was considered. In the A375 model, significant differences in tumor progression were evaluated by the Kaplan-Meier survival analysis followed by logrank test, using as end-point a tumor weight of $1000 \mathrm{mg}$.

\subsection{Immunohistochemical analysis}

Immunohistochemical analysis of monoclonal mouse anti-human Ki67 (M7240, DAKO Italia, Milano, IT) (1:50 dilution, 60 min, room temperature) was carried out on 3- $\mu \mathrm{m}$ thick paraffin sections as described [18]. Immunohistochemical scoring was determined without any knowledge of which group the mice belonged to. The number of positive (brown stained) cells was determined as a percentage of the total number of cells counted in 5 separate fields of 100 cells, in non necrotic areas of 8 tumor section, in each group.

\subsection{Immunoblotting}

Samples $(80 \mu \mathrm{g}$ aliquots as determined by the Bradford assay, Bio-Rad Laboratories, Inc., Hercules, CA) were separated on SDS-PAGE and immunoblot analyses were carried out as described [19]. Antibodies used included: rabbit anti-phospho-p44/42 mitogen-activated protein kinase (p-p44/42 MAPK) (Thr202/Tyr204), and anti-total-p44/42 MAP kinase (1:1000); rabbit anti-phospho-AKT (p-AKT) (Ser473), and anti-total-AKT (1:1000) (all from Cell Signaling Technology, Boston, MA); mouse anti- $\beta$-actina (1:4000). Protein level were quantified by densitometric analysis using the Scion Image Beta 4.02 software package (Scion Corporation, Frederick, MD, USA). 


\subsection{Angiogenesis Assay}

The method described by Passaniti et al. [20] was used, with some modifications. Briefly, bFGF (300 ng/ml) was incorporated into liquid Matrigel $(12.5 \mathrm{mg} / \mathrm{ml})$ and a plug of $0.45 \mathrm{ml}$ Matrigel was injected subcutaneously into the ventral abdominal wall of each female athymic mice. Mice (10/group) received via gavage sanguinarine ( $5 \mathrm{mg} / \mathrm{kg} / \mathrm{day})$ or vehicle, daily, for 6 days from the day of Matrigel injection. At day 7, the pellet was removed, and the hemoglobin content was measured by the Drabkin's procedure (Drabkin reagent kit). Matrigel and basic Fibroblast Growth Factor (bFGF) were obtained from Becton Dickinson (Bedford, MA).

\subsection{Statistical methods}

Tumor weight data were analyzed by repeated-measures ANOVA, followed by the

Bonferroni method as post-test. To determine significant differences in tumor progression between groups, the Kaplan-Meier survival analysis was used, followed by logrank test (A375 only). The remaining data were analyzed by the unpaired $t$ test. Statistical analysis was carried out with GraphPad Prism5 Software (San Diego, CA, USA). P $<0.05$ was used as the critical level of significance. 


\section{RESULTS}

\subsection{In vitro studies}

The benzophenanthridine alkaloids sanguinarine and cheleritrine, tested in B16 melanoma 4A5 cell line, yielded IC50 values of $1.96 \pm 0.22$, and $2.9 \pm 0.22 \mu \mathrm{M}$ respectively, following 72 hours of drug exposure; these results clearly pointed out that sanguinarine was more active than cheleritrine against melanoma cancer cells, and, for this reason, it was selected for subsequent in vivo investigations. A potential effect of drugs on the nuclear structure was assessed by Comet assay and results are shown in Fig. 1A and B: both compounds were able to induce DNA breaks, but the effect was greater upon sanguinarine treatment. Topo-I was then investigated as a possible target. A representative experiment is shown in Fig. $2 \mathrm{~A}$. Notably, both sanguinarine and cheleritrine were able to markedly inhibit the process of DNA relaxation. This result prompted us to investigate whether the substances under investigation, rather than a specific activity on Topo-I, were DNA intercalating agents. This hypothesis was tested through the DNA unwinding assay. Several topoisomers of a DNA plasmid are noticeable in normal isotonic buffers, but when an intercalating agent is added to DNA, the structure of DNA changes and the number of possible topoisomers decreases. Using again a p-Bluescript plasmid, and Ethidium Bromide as positive control, this assay clearly demonstrated that both the agents were able to intercalate into the DNA structure (Fig. 2B).

\subsection{In vivo studies}

\subsubsection{Antitumor efficacy}

In the first set of experiments, C57BL/6 female mice were injected s.c. with B16 melanoma 4A5 cells, a very aggressive syngenic tumor with a rapid growth rate, and treated orally with sanguinarine $5 \mathrm{mg} / \mathrm{kg} /$ day or vehicle, until the end of the study. Results showed a relevant therapeutic activity with suppression of tumor growth in comparison with control mice 
( $<<0.01$, by repeated-measures ANOVA, followed by Bonferroni test, Fig. 3A). A TWI of $52 \%$ was recorded on day 18 of the study. Similar results were also obtained using A375, a tumor with a slower rate of in vivo growth; also in this case, sanguinarine-treated mice had a significant therapeutic effect, showing a significant tumor growth inhibition in comparison to control mice (p $<0.05$, Fig. 3C). A TWI of $58 \%$ was recorded on day 60 of the study. In addition, results from the Kaplan- Meier analysis (Fig. 3E) showed that treatment significantly improved time to tumor progression versus control mice $(\mathrm{p}<0.05)$, the end point criterion being tumors grown to $1000 \mathrm{mg}$. By day 77 of the study, there were three tumor-free mice; these mice were no longer dosed, showing no evidence of tumor after a further treatment-free observation period of 60 days (i.e. day 137 of the study). Body weight (Fig. 3B and 3D) and food consumption (data not shown) did not significantly differ among treatment groups in both studies, thus confirming the absence of drug toxicity at the selected dose level.

\subsubsection{Effect on tumor proliferation}

Proliferation of A375 cells significantly differed among groups (Fig. 4A and B). An average value of $66.0 \pm 5.1 \%$ (mean \pm SEM) Ki67 positive cells was recorded in control tumors. A reduction in proliferation was observed in animal receiving $5 \mathrm{mg} / \mathrm{kg} /$ day sanguinarine, the mean value of positive stained cells being $50.0 \pm 3.2 \%$; this change reached statistical significance, with respect to controls ( $\mathrm{p}=0.03$ ).

\subsubsection{Effect on $p M A P K / M A P K$ and $p A K T / A K T$ levels in tumors}

Representative immunoblots of the total and the phosphorylated forms of the proteins are shown in Fig. 4C and 4E. Results obtained showed that the ratio p-p44/42 MAPK/p44/42 MAPK was decreased in A375 tumors following treatment with $5 \mathrm{mg} / \mathrm{kg} /$ day sanguinarine, this change reaching statistical significance (Fig. 4D, $\mathrm{p}=0.04$ vs controls). Tumors from treated mice also tended to have a lower pAKT/AKT ratio compared to controls $(\mathbf{F i g} . \mathbf{4 F}, \mathrm{p}=$ 0.07). 


\subsubsection{Angiogenesis in vivo}

Daily oral doses of $5 \mathrm{mg} / \mathrm{kg}$ sanguinarine for 6 days significantly reduced the angiogenic response induced by bFGF (Fig. 5A and B). The mean hemoglobin content of bFGFcontaining pellets was significantly lower $(p=0.02)$ in sanguinarine-treated mice $(0.05 \pm$ $0.009 \mathrm{~g} / \mathrm{dl}$, mean $\pm \mathrm{SEM})$ than in vehicle-treated mice $(0.11 \pm 0.012 \mathrm{~g} / \mathrm{dl}$, mean $\pm \mathrm{SEM})$. 


\section{DISCUSSION}

Experimental data from the present study support the concept that sanguinarine can be effective in melanoma skin cancer. During a cellular screening of benzophenanthridine alkaloids we found that the drug resulted more active than the analogous compound cheleritrine against the murine cell line B16 melanoma 4A5, and that it mainly acts as an intercalating agent producing DNA breaks. This finding is in keeping with earlier data from Maiti and colleagues [21], showing that sanguinarine strongly interacts with DNA, binding, like ethidium bromide, by monofunctional mode of intercalation. Importantly, previous Authors have suggested that the cytotoxic and the DNA damaging effects of sanguinarine are selective against cancer cells as compared to normal cells [7,22], a finding, however, not confirmed by other studies [23]. We did not evaluate the effects of sanguinarine on normal melanocytes in the present work; while not addressing safety issues at this time, we believe, however, that properly designed in vitro and in vivo experiments are needed to exploit the undesired toxic effect of this alkaloid to normal tissue. Indeed, toxicity is a crucial matter in the development of anticancer drugs, often derailing clinical trials.

The activity of sanguinarine in melanoma was then confirmed in vivo, against a transplantable murine tumor grown in a syngeneic host (B16 melanoma 4A5 in C57BL/6 mice), and against a human tumor xenograft grown in immunodeficient mice (A375 in athymic nude mice). Because of an intact tumor host environment, the syngeneic transplantable mouse tumor model represents a valuable experimental model for the evaluation of therapies that require immune response, or that target specific components of blood vessels or the extracellular matrix. Conversely, the human xenograft tumor grown in nude mice exhibits a proliferative pattern with molecular and pathophysiological features similar to patient-tumor characteristics. In both experimental models, oral sanguinarine administration reduced by more than 50\% tumor development, compared to controls. In A375 tumors, this result was 
associated with a significant decrease in the proliferation marker Ki67, and with a reduction in the activated MAPK and AKT. These latter findings are particularly important when considering that the RAS/RAF/MEK/ERK (MAPK) and PI3K/AKT (AKT) signaling pathways are constitutively activated through multiple mechanisms, and appear to play a major role in melanoma development and progression, this implying that combined targeting of MAPK and AKT signaling pathways is a promising strategy for melanoma treatment [24]. Notably, 3 out of 11 A375-bearing treated mice were tumor-free at the end of treatment (i.e. day 77 of the study), showing no evidence of tumor after a further, treatment-free, observation period of 60 days. It is worthy to note that preliminary pharmacokinetics data obtained in our laboratory indicated that within two hours following oral treatment with $5 \mathrm{mg} / \mathrm{kg}$ sanguinarine, the compound achieved relevant levels in plasma and in B164A5 tumors (unpublished data).

The antiproliferative activity of sanguinarine has been mainly attributed to its involvement on critical molecular events regulating the cell cycle and the apoptotic machinery $[7,9,25,26]$, yet its observed therapeutic effect cannot be ascribed solely to a direct antiproliferative activity, as indicated by data from the present study, showing that the role of the alkaloid in tumor suppression is more complex than that of merely antiproliferative cytotoxic agent. Rather, an effect on tumor angiogenesis seems to play a decisive role. Other Authors have previously reported that sanguinarine is a potent antiangiogenic natural product, able to suppress in vitro VEGF-induced endothelial cell migration, sprouting, and survival [27]. In vivo studies confirmed its activity as a potent inhibitor of blood vessel formation in the mouse Matrigel plug assay (the drug was incorporated into the Matrigel), and in the chicken chorioallantoic membrane assay (the drug was air-dried on plastic discs then applied to the CAM surface) [27]. To our knowledge, the present study is the first to report an effect of sanguinarine as angiogenesis inhibitor, following systemic administration to experimental 
animals. Moreover, Western analysis on A375 tumors showed a relevant reduction in AKT activation in treated mice when compared to controls. Notably, this finding is in keeping with previous findings reported by other Authors demonstrating, in in vitro models, that the antiangiogenetic effect of sanguinarine could occur partly through blocking the VEGFinduced PI 3'-kinase/AKT activation, a pivotal event in angiogenesis signaling [27,28]. One mechanism by which VEGF-targeted therapy may be of benefit in cancer treatment is by counteracting the up-regulation of VEGF expression following genotoxic stress induced by chemotherapy or radiation therapy [29]. Notably, treatment of human melanoma cells with dacarbazine caused an increase in secreted VEGF-A, and interleukin 8 (IL8) [30], and dacarbazine-resistant melanoma cell lines demonstrated increased growth in vivo with increased microvessel density [31]. Altogether these findings support an exciting hypothesis of opportunity for testing combination regimens between sanguinarine and cytotoxic drugs currently approved for the treatment of advanced melanoma.

In conclusion, our results suggest that sanguinarine exerts a profound anti-cancerous effect through a combined action on several critical determinants of tumor progression, such as angiogenesis, and cell proliferation. To our knowledge the present study is the first reporting an antiproliferative and antiangiogenic effect of sanguinarine following oral administration to mice. Notably, its inhibitory effects on angiogenesis and tumor progression were observed in mice at a dosage devoid of apparent toxicity, although additional studies need to be carried out to fully characterize the safety profile of the drug. Overall, findings from the present study make sanguinarine a likely candidate for further evaluation in melanoma treatment. 
1

\section{Acknowledgements}

This study was supported in part by the Ministero Istruzione Università e Ricerca (Decreto

No. 1587). Sanguinarine and Cheleritrine were donated by INDENA s.p.a. 


\section{Literature Cited}

1. Ferlay J, Bray F, Pisani P, Parkin DM. GLOBOCAN 2002. Cancer Incidence, Mortality and Prevalence Worldwide. IARC Cancer Base No. 5 Version 2.0. Lyon, France: IARCPress; 2004.

2. Jemal A, Siegel R, Ward E, Hao Y, Xu J, Murray T, Thun MJ. Cancer statistics, 2008. CA Cancer J Clin 2008; 58:71-96.

3. Gray-Schopfer V, Wellbrock C, Marais R. Melanoma biology and new targeted therapy. Nature 2007; 445:851-7.

4. Tarhini AA \& Agarwala S S. Cutaneous melanoma: available therapy for metastatic disease. Dermatol Ther 2006; 19:19-25.

5. Kirkwood JM, Moschos S, \& Wang W. Strategies for the development of more effective adjuvant therapy of melanoma: current and future explorations of antibodies, cytokines vaccines, and combinations. Clinical Cancer Res 2006; 12:2331s-2336s.

6. Mukherjee AK, Basu S, Sarkar N and Ghosh AC. Advances in cancer therapy with plant based natural products. Current Med Chem 2001; 8:1467-1486.

7. Ahmad N, Gupta S, Husain MM, Heiskanen KM, Mukhtar H. Differential antiproliferative and apoptotic response of sanguinarine for cancer cells versus normal cells. Clinical Cancer Res 2000; 6:1524-1528.

8. Chmura SJ, Dolan ME, Cha A, Mauceri HJ, Kufe DW, Weichselbaum RR. In vitro and in vivo activity of protein kinase $\mathrm{C}$ inhibitor chelerythrine chloride induces tumor cell toxicity and growth delay in vivo. Clinical Cancer Res 2000; 6:737-42.

9. Adhami VM, Aziz MH, Reagan-Shaw SR, Nihal M, Mukhtar H, Ahmad N. Sanguinarine causes cell cycle blockade and apoptosis of human prostate carcinoma cells via modulation of cyclin kinase inhibitor-cyclin-cyclin-dependent kinase machinery. Mol Cancer Ther 2004; 3: 933-940. 
10. Chaturvedi MM, Kumar A, Darnay BG, Chainy GB, Agarwal S, Aggarwal BB. Sanguinarine (pseudochelerythrine) is a potent inhibitor of $\mathrm{NF}-\kappa \mathrm{B}$ activation, I $\mathrm{B} \alpha$ phosphorylation, and degradation. J Biol Chem 1997; 272:30129-30134.

11. Ding Z, Tang SC, Weerasinghe P, Yang X, Pater A, Liepins A. The alkaloid sanguinarine is effective against multidrug resistance in human cervical cells via bimodal cell death. Biochem Pharmacol 2002; 63:1415-1421.

12. Serafim TL, Matos JA, Sardão VA, Pereira GC, Branco AF, Pereira SL, et al. Sanguinarine cytotoxicity on mouse melanoma K1735-M2 cells-Nuclear vs. mitochondrial effects. Biochem Pharmacol 2008; 76:1459-75.

13. Motulsky HJ and Ransnas LA. Fitting curves to data using nonlinear regression: a practical and nonmathematical review. FASEB J 1987; 1:365-374.

14. Raspaglio G, Ferlini C, Mozzetti S, Prislei S, Gallo D, Das N, et al. Thiocolchicine dimers: a novel class of topoisomerase-I inhibitors. Biochem Pharmacol 2005;69:113-21.

15. Pommier Y, Schwartz RE, Zwelling LA and Kohn KW. Effects of DNA intercalating agents on topoisomerase II induced DNA strand cleavage in isolated mammalian cell nuclei. Biochemistry 1985; 24:6406-6410.

16. United Kingdom Co-ordinating Committee on Cancer Research (UKCCCR) Guidelines for the Welfare of Animals in Experimental Neoplasia (Second Edition). Br J Cancer $1998 ; 77: 1-10$

17. Corbett T, Valeriote F, LoRusso P, Polin L, Panchapor C, Pugh S, et al. In vivo methods for screening and preclinical testing. In Teicher BA (ed) Anticancer Drug Development Guide. Humana Press, Totowa, New Jersey, 1997:75-99.

18. Gallo D, Zannoni GF, Martinelli E, Ferlini C, Fabrizi M, Riva A, et al. Estradiol and phytoestrogens differently influence the rodent postmenopausal mammary gland. Menopause 2006; 13:72-9. 
19. Gallo D, Zannoni GF, De Stefano I, Mosca M, Ferlini C, Mantuano E, et al. Soy phytochemicals decrease nonsmall cell lung cancer growth in female athymic mice. J Nutr 2008;138:1360-4.

20. Passaniti A, Taylor RM, Pili R. A simple, quantitative method for assessing angiogenesis and antiangiogenic agents using reconstituted basement membrane, heparin, and fibroblast growth factor. Lab Investig 1992; 67:519-528.

21. Maiti M, Nandi R and Chaudhuri K. Sanguinarine: a monofunctional intercalation alkaloids. FEBS Lett 1982; 142: 280-284.

22. Kaminskyy V, Lin KW, Filyak Y, Stoika R. Differential effect of sanguinarine, chelerythrine and chelidonine on DNA damage and cell viability in primary mouse spleen cells and mouse leukemic cells. Cell Biol Int 2008; 32:271-7.

23. Malíková J, Zdarilová A, Hlobilková A, Ulrichová J. The effect of chelerythrine on cell growth, apoptosis, and cell cycle in human normal and cancer cells in comparison with sanguinarine. Cell Biol Toxicol 2006; 22:439-53.

24. Meier F, Schittek B, Busch S, Garbe C, Smalley K, Satyamoorthy K, et al. The RAS/RAF/MEK/ERK and PI3K/AKT signaling pathways present molecular targets for the effective treatment of advanced melanoma. Front Biosci 2005; 10:2986-3001.

25. Han MH, Kim SO, Kim GY, Kwon TK, Choi BT, Lee WH, et al. Induction of apoptosis by sanguinarine in $\mathrm{C} 6$ rat glioblastoma cells is associated with the modulation of the Bcl-2 family and activation of caspases through downregulation of extracellular signal-regulated kinase and Akt. Anticancer Drugs 2007; 18:913-21.

26. Kim S, Lee TJ, Leem J, Choi KS, Park JW, Kwon TK. Sanguinarine-induced apoptosis: generation of ROS, down-regulation of Bcl-2, c-FLIP, and synergy with TRAIL. J Cell Biochem 2008; 104:895-907. 
27. Eun JP, Koh GY. Suppression of angiogenesis by the plant alkaloid, sanguinarine. Biochem Biophys Res Commun 2004; 317:618-24.

28. Basini G, Bussolati S, Santini SE, Grasselli F. Sanguinarine inhibits VEGF-induced angiogenesis in a fibrin gel matrix. Biofactors 2007; 29:11-8.

29. Ellis LM, Hicklin DJ. VEGF-targeted therapy: mechanisms of anti-tumour activity. Nat Rev Cancer 2008; 8:579-91. Review.

30. Lev DC, Ruiz M, Mills L, McGary EC, Price JE, Bar-Eli M. Dacarbazine causes transcriptional up-regulation of interleukin 8 and vascular endothelial growth factor in melanoma cells: a possible escape mechanism from chemotherapy. Mol Cancer Ther $2003 ; 2: 753-63$.

31. Lev DC, Onn A, Melinkova VO, Miller C, Stone V, Ruiz M, et al. Exposure of melanoma cells to dacarbazine results in enhanced tumor growth and metastasis in vivo. J Clin Oncol $2004 ; 22: 2092-100$. 


\section{FIGURE LEGENDS}

Figure 1 -Comet assay performed in isolated nuclei in the presence of the vehicle (Control, DMSO 0.1\%), sanguinarine $(0.1,0.25,0.5,1,2.5$ and $5 \mu \mathrm{M})$, cheleritrine $(0.1,0.25,0.5,1$, 2.5 and $5 \mu \mathrm{M})$, or $\mathrm{H}_{2} \mathrm{O}_{2}(50 \mu \mathrm{M})$ as positive control. (A) Representative image of the experiment reported in the bar chart. (B) Bar chart showing the results of the \% Tail DNA. This experiment was repeated three times with similar results. $*=p<0.05, * *=p<0.01, * * *$ $=\mathrm{p}<0.001$ vs Control

Figure 2 (A) Agarose gel electrophoresis for a cell free DNA relaxation assay of a supercoiled pBluescript plasmid DNA, treated with the tested compounds from 2 to $30 \mathrm{~min}$. Relaxed DNA topoisomers (rel) slowly migrate in the gel as compared to supercoiled DNA (sc). After 30 min the full DNA relaxation is obtained in control lanes (DMSO 0.5\%). Sanguinarine and cheleritrine strongly inhibit the activity of Topoisomerase-I at $50 \mu \mathrm{M}$; CPT was used as a positive control. (B) Representative image of the agarose gel electrophoresis for DNA unwinding assay. Several topoisomers of a DNA plasmid are noticeable in normal isotonic buffer (rel, Ctrl 15'), but when an intercalating agent is added to DNA the structure of DNA changes, and the number of topoisomers decreases, as occurred in the presence of sanguinarine and cheleritrine $(50 \mu \mathrm{M})$, with presence of supercoiled (sc) DNA. Ethidium Bromide was used as positive control. To confirm full relaxation of DNA, one sample was terminated with SDS after $75 \min \left(\mathrm{Ctrl}_{75}\right)$ ). This experiment was repeated three times with similar results.

Figure 3 - (A) B16 melanoma 4A5 tumor growth, and (B) body weight, of female C57BL6 mice receiving 0 (control) or $5 \mathrm{mg} / \mathrm{kg}$ /day sanguinarine (means $\pm \mathrm{SEM}, \mathrm{n}=10 /$ group); *different from control at that time, $\mathrm{p}<0.01$. (C) A375 xenograft growth, and (D) body weight 
of female athymic mice receiving 0 (control) or $5 \mathrm{mg} / \mathrm{kg} /$ day sanguinarine (mean $\pm \mathrm{SEM}$, $\mathrm{n}=11-12 /$ group at the start of the study. Data are reported until $n=5 /$ group); $*$ different from control at that time, $p<0.05$. (E) Kaplan-Meier curves showing the tumor progression of female athymic mice with A375 xenografts ( $\mathrm{n}=11-12 /$ group). The end-point was tumor weight $=1000 \mathrm{mg} . *=p<0.05 v s$ Control (Logrank test). By day 77 of the study, there were three tumor-free mice; these mice were no longer dosed, showing no evidence of tumor after a further treatment-free observation period of 60 days (i.e. day 137 of the study).

Figure 4 - (A) Representative immunohistochemical localization of Ki67, and (B) tumor proliferation, in A375 xenografts from female athymic mice receiving 0 (control), or 5 $\mathrm{mg} / \mathrm{kg} /$ day sanguinarine (mean $\pm \mathrm{SEM}, \mathrm{n}=8$ tumors/group). Magnification 20x. (C, E) Representative western blots, and (D, F) protein expression for p-p44/42MAPK/total-p44/42 MAPK and p-AKT/AKT, respectively, in A375 tumors from female athymic mice receiving 0 (control), or $5 \mathrm{mg} / \mathrm{kg} /$ day sanguinarine (mean $\pm \mathrm{SEM}, \mathrm{n}=8$ tumors/group).

Figure 5 - Effects of sanguinarine on in vivo angiogenesis in the Matrigel plug assay. (A) Macroscopic evaluation of the Matrigel plugs. Angiogenic plugs appear red-orange with small curly vessels, non-angiogenic plugs appear translucent. (B) Hemoglobin content $(\mathrm{g} / \mathrm{dl})$ of the pellets in control and sanguinarine $(5 \mathrm{mg} / \mathrm{kg} /$ day os $)$-treated mice. The box extend to the $25^{\text {th }}$ and $75^{\text {th }}$ percentiles; the horizontal bars indicate median values, and whiskers minimum and maximum values ( $\mathrm{n}=10$ /group). 
Figure 1

A

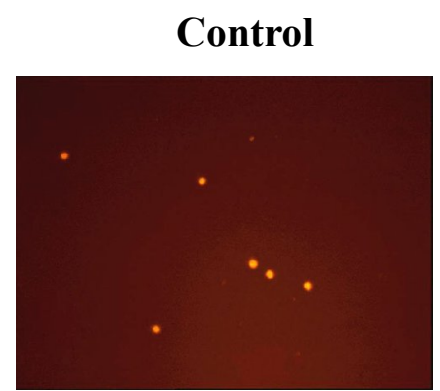

$\mathrm{H}_{2} \mathrm{O}_{2} \mathbf{5 0} \mu \mathrm{M}$
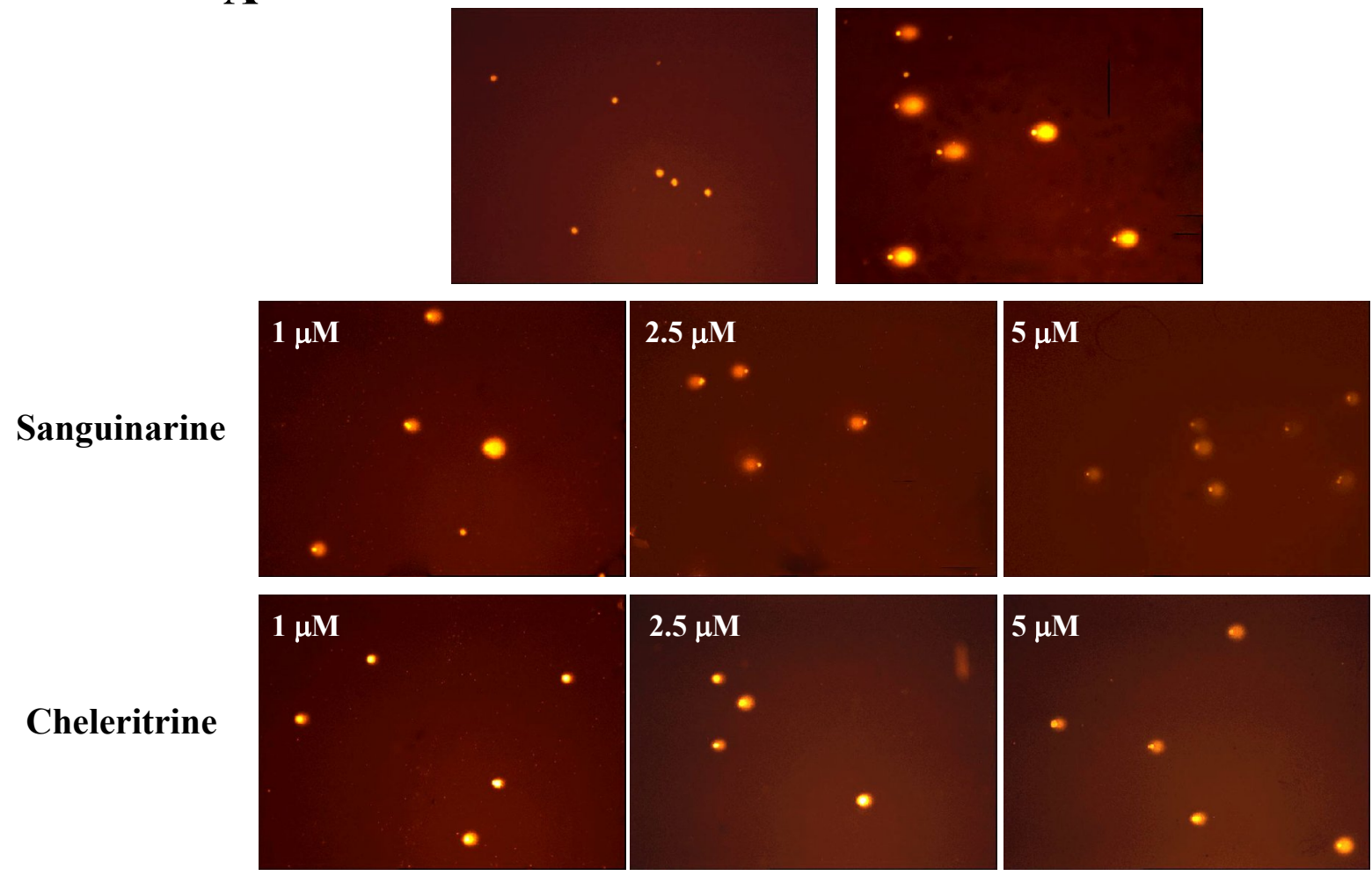

B

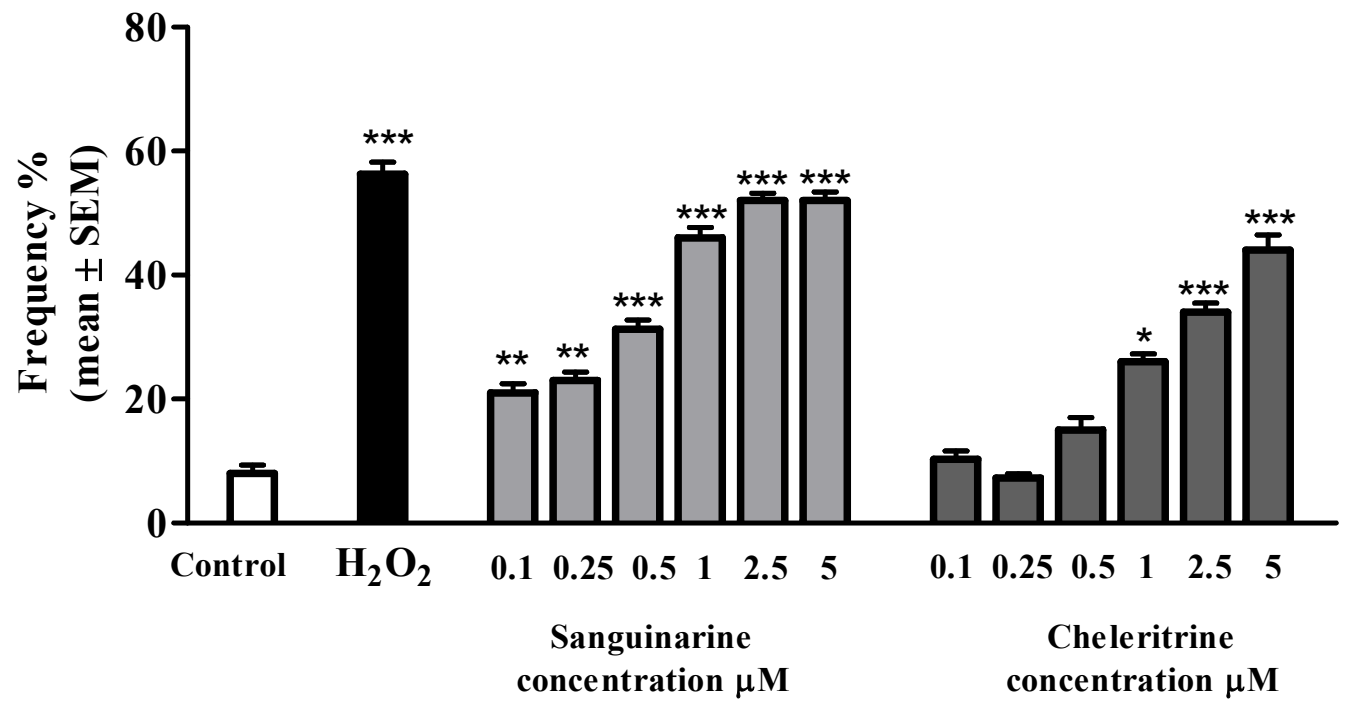




\section{Figure 2}

A

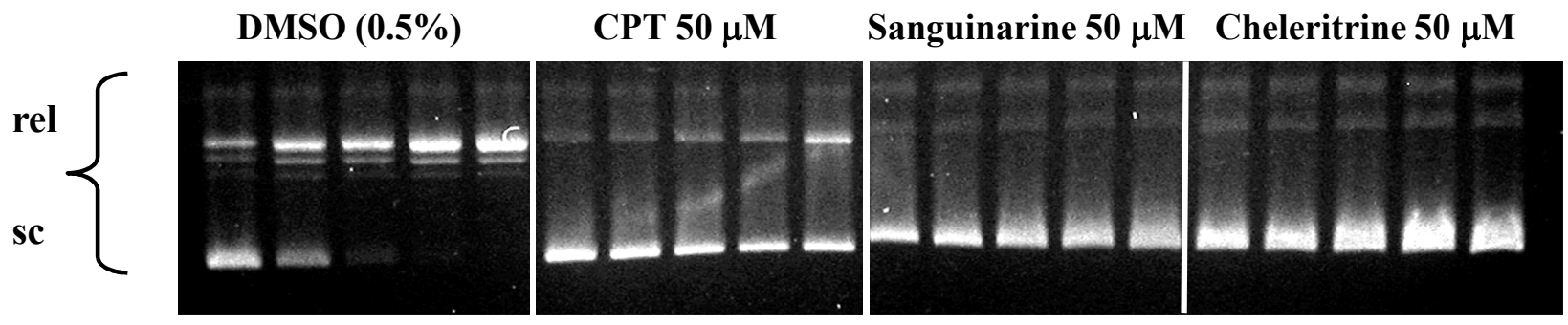

$\begin{array}{lllllllllllllllllllll}\text { Time (min) } & 2 & 5 & 10 & 15 & 30 & 2 & 5 & 10 & 15 & 30 & 2 & 5 & 10 & 15 & 30 & 2 & 5 & 10 & 15 & 30\end{array}$

B

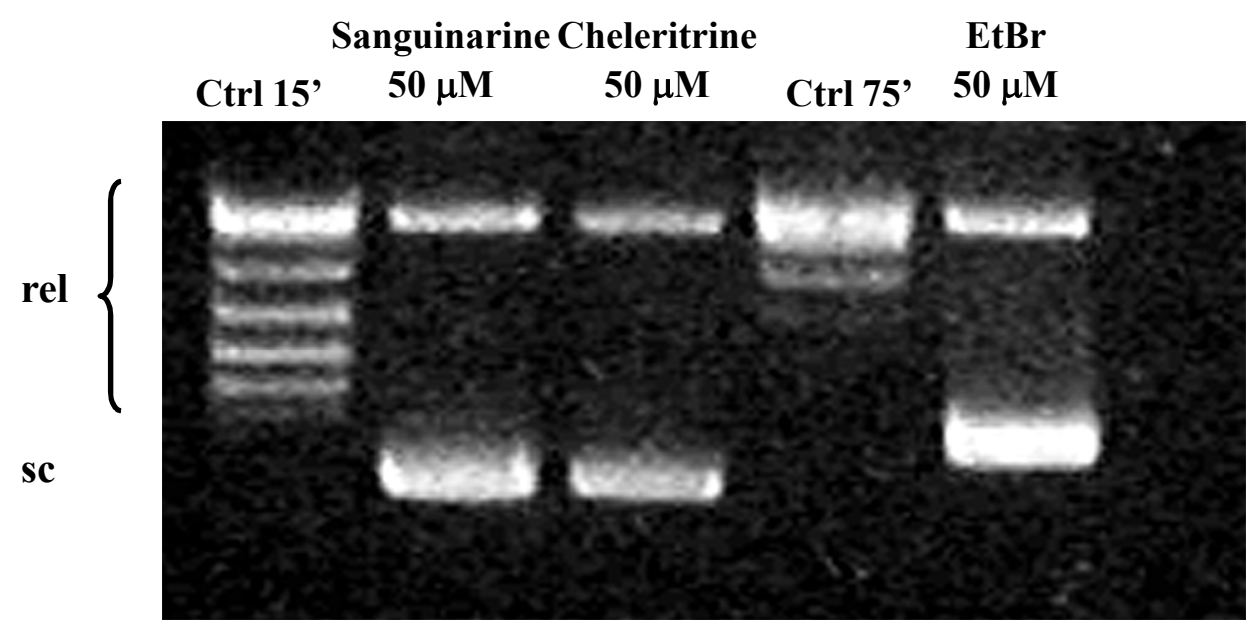




\section{Figure 3}

A

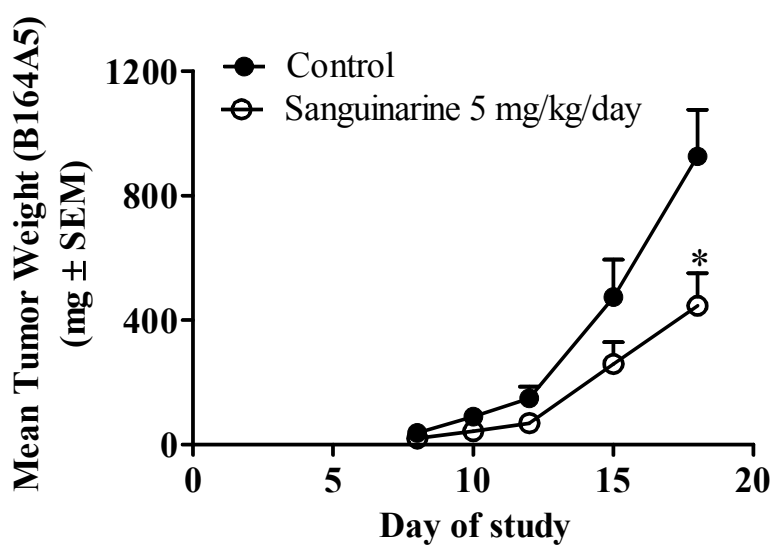

C

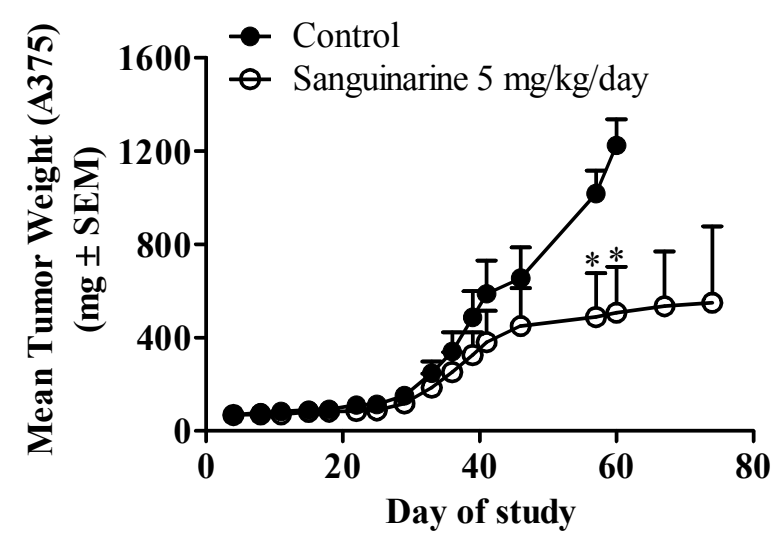

B

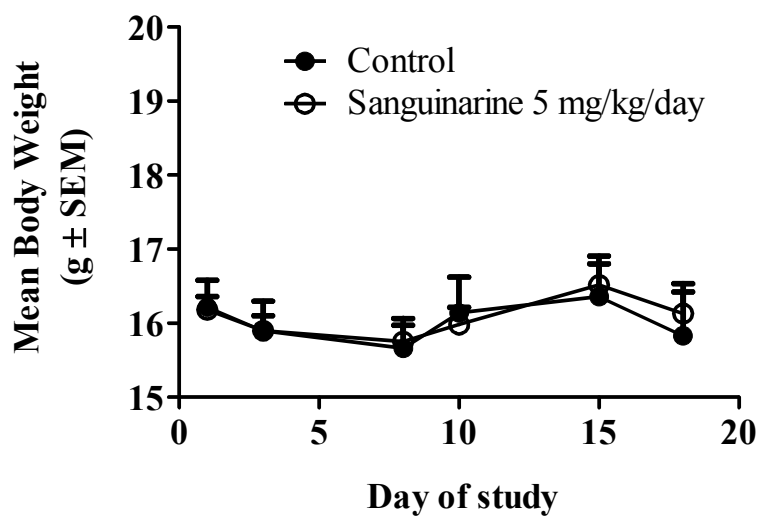

D

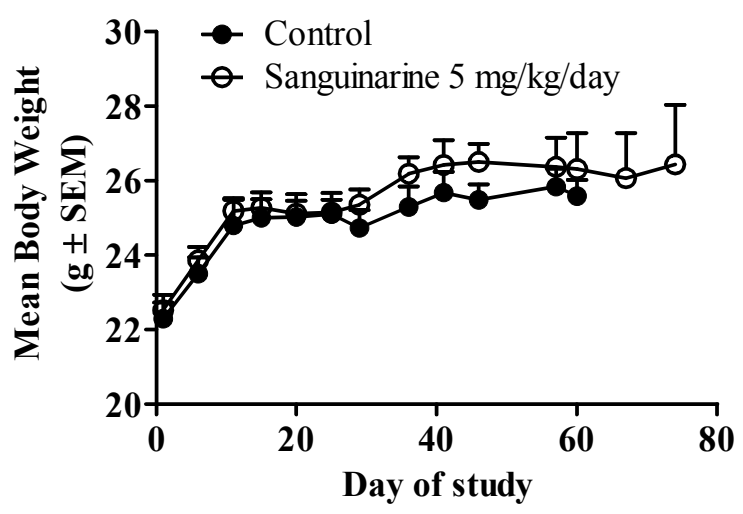

E

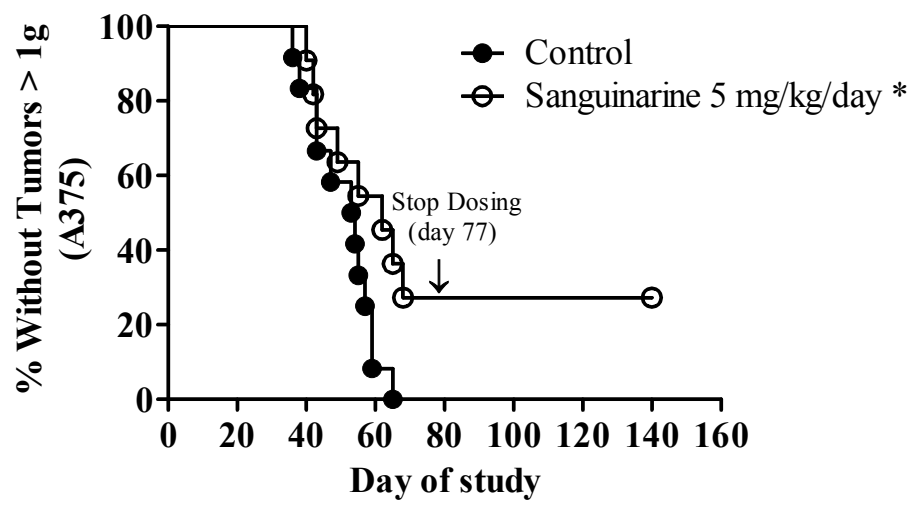




\section{Figure 4}

A

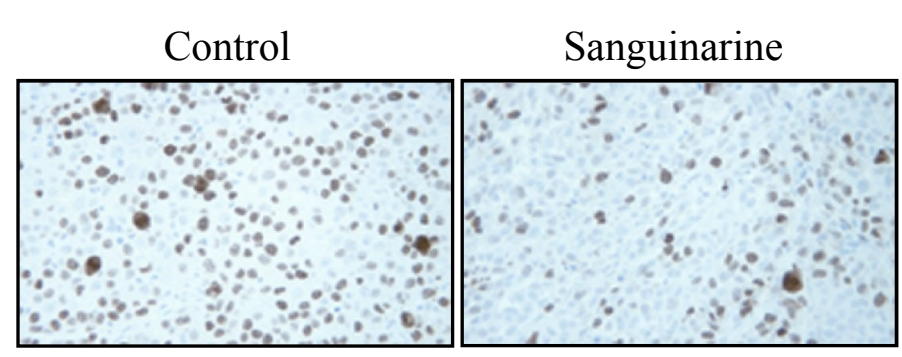

Ki67
B

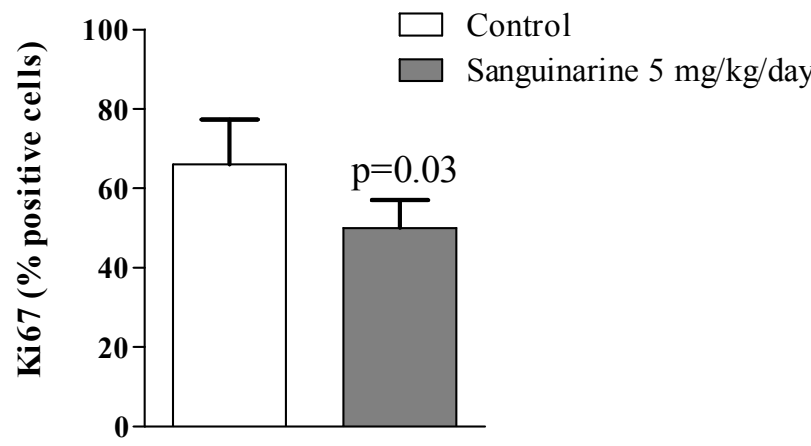

C

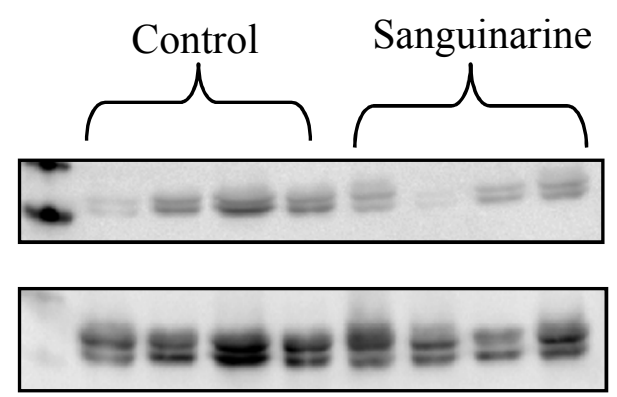

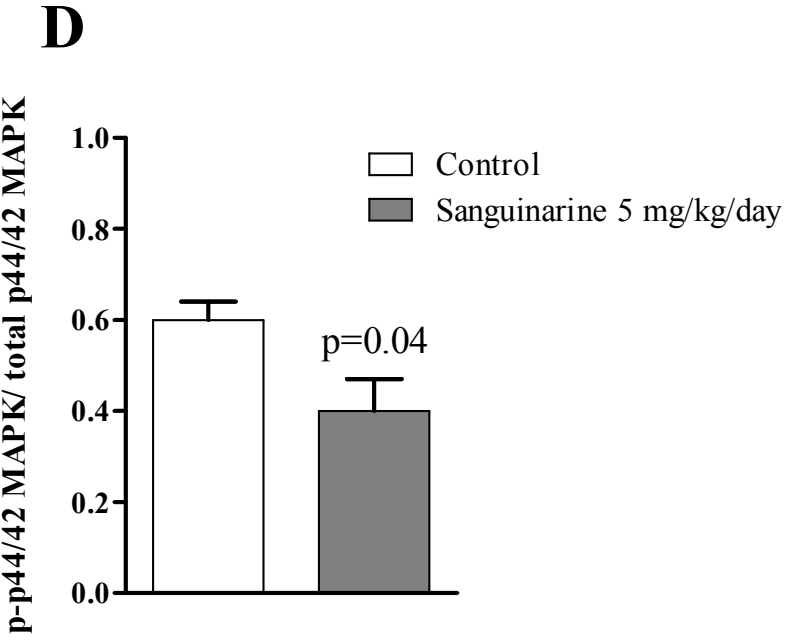

F

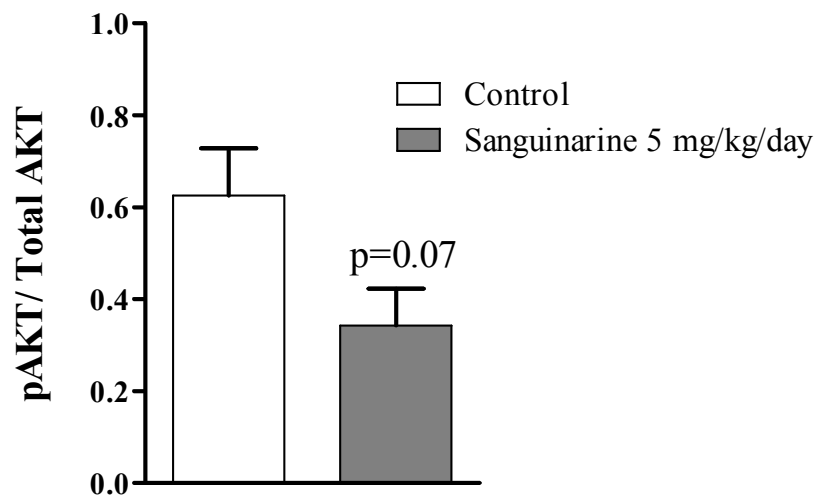


Figure 5

A

CONTROL

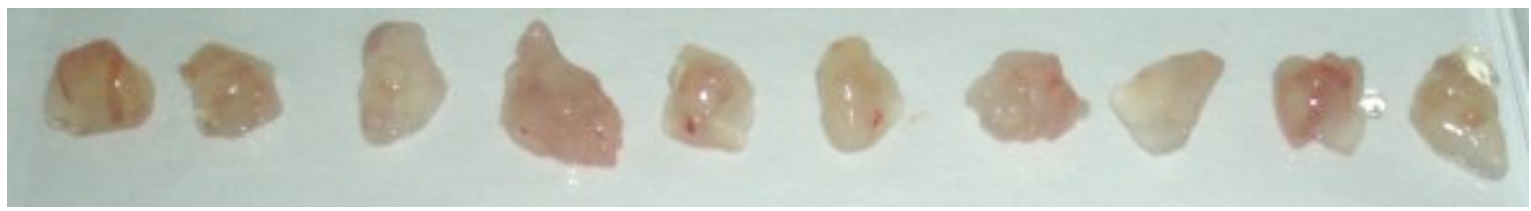

SANGUINARINE $5 \mathrm{mg} / \mathrm{kg} / \mathrm{day}$

B

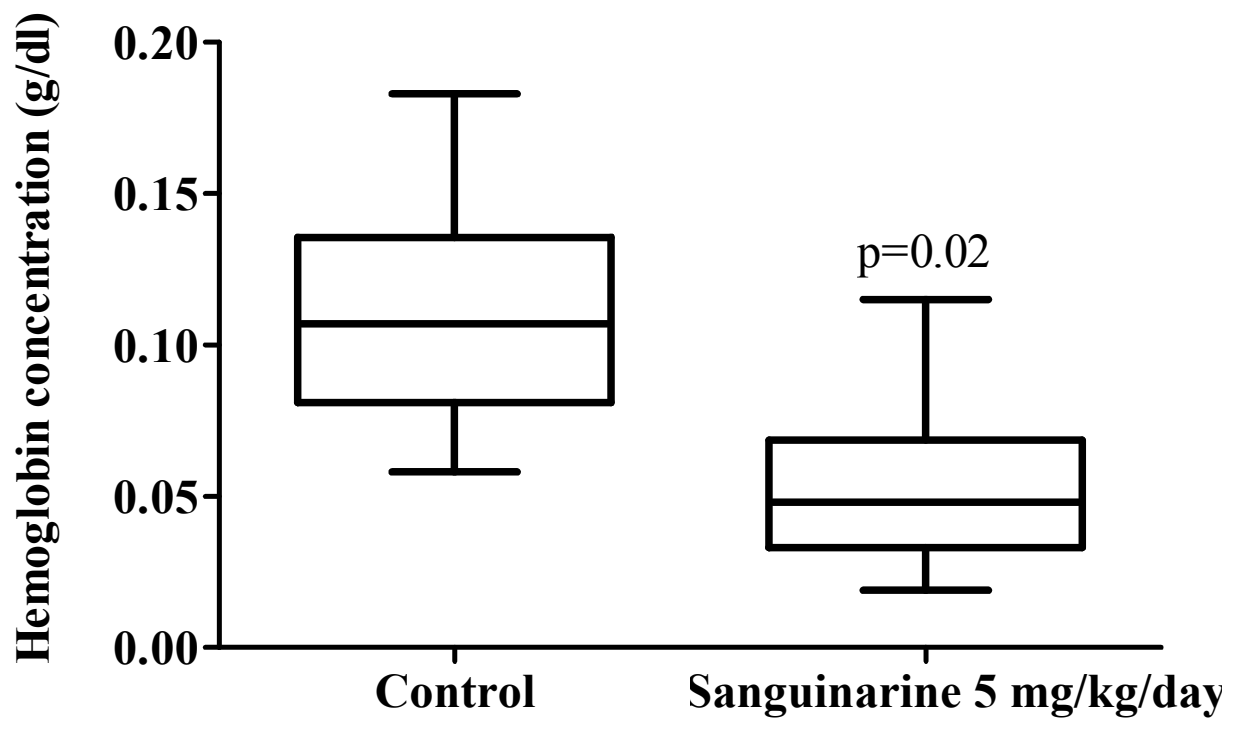


Preclinical in vivo antiproliferative and antiangiogenic effects of Sanguinarine in melanoma
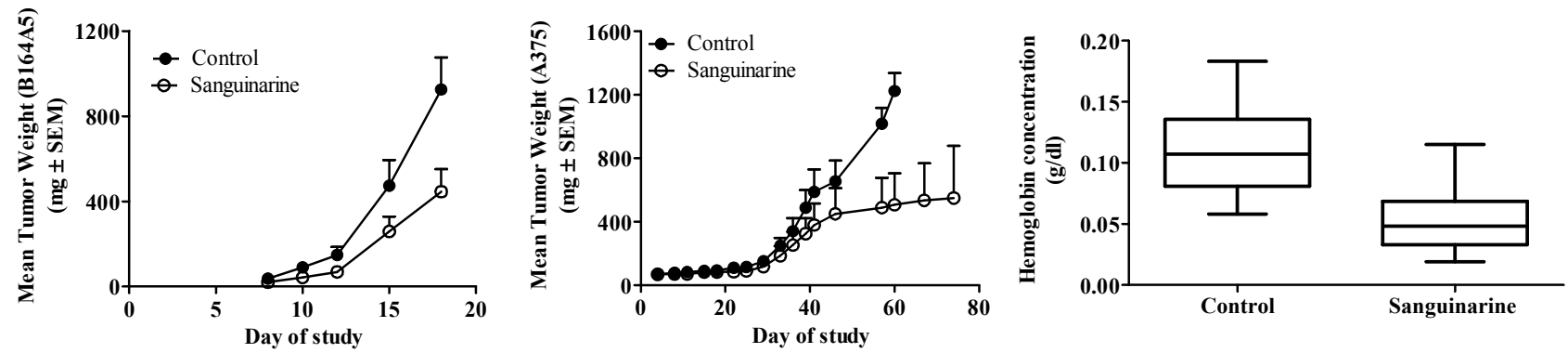